\title{
Clinical Article \\ Effects of cerebral perfusion pressure and increased fraction of inspired oxygen on brain tissue oxygen, lactate and glucose in patients with severe head injury
}

\author{
M. Reinert ${ }^{1}$, A. Barth ${ }^{1}$, H. U. Rothen ${ }^{2}$, B. Schaller ${ }^{1}$, J. Takala ${ }^{2}$, and R. W. Seiler ${ }^{1}$ \\ ${ }^{1}$ Department of Neurosurgery, Inselspital Bern, University of Bern, Switzerland \\ ${ }^{2}$ Department of Intensive Care Medicine, Inselspital Bern, University of Bern, Switzerland
}

Published online June 4, 2003

(C) Springer-Verlag 2003

\section{Summary}

Objective. The purpose of the study was to measure the effects of increased inspired oxygen on patients suffering severe head injury and consequent influences on the correlations between CPP and brain tissue oxygen (PtiO2) and the effects on brain microdialysate glucose and lactate.

Methods. In a prospective, observational study 20 patients suffering severe head injury (GCS $\leq 8$ ) were studied between January 2000 and December 2001. Each patient received an intraparenchymal ICP device and an oxygen sensor and, in 17 patients brain microdialysis was performed at the cortical-subcortical junction. A $6 \mathrm{~h} 100 \%$ oxygen challenge $\left(\mathrm{FIO}_{2}\right.$ 1.0) (Period $\left.A\right)$ was performed as early as possible in the first 24 hours after injury and compared with a similar 6 hour period following the challenge (Period B). Statistics were performed using the linear correlation analysis, one sample t-test, as well as the Lorentzian peak correlation analysis.

Results. $\mathrm{FIO}_{2}$ was positively correlated with $\mathrm{PtiO} 2(\mathrm{p}<0.0001)$ over the whole study period. PtiO2 was significantly higher $(\mathrm{p}<0.001)$ during Period A compared to Period B. CPP was positively correlated with $\mathrm{PtiO} 2(\mathrm{p}<0.001)$ during the whole study. $\mathrm{PtiO} 2$ peaked at a $\mathrm{CPP}$ value of $78 \mathrm{mmHg}$ performing a Lorentzian peak correlation analysis of all patients over the whole study. During Period A the brain microdialysate lactate was significantly lower $(\mathrm{p}=0.015)$ compared with Period $B$. However the brain microdialysate glucose remained unchanged.

Conclusion. PtiO2 is significantly positively correlated with $\mathrm{FIO}_{2}$, meaning that $\mathrm{PtiO} 2$ can be improved by the simple manipulation of increasing $\mathrm{FIO}_{2}$ and $\mathrm{ABGAO}$. $\mathrm{PtiO} 2$ is positively correlated with $\mathrm{CPP}$, peaking at a $\mathrm{CPP}$ value of $78 \mathrm{mmHg}$. Brain microdialysate lactate can be lowered by increasing $\mathrm{PtiO} 2$ values, as observed during the oxygen challenge, whereas microdialysate glucose is unchanged during this procedure. Extension of the oxygen challenge time and measurement of the intermediate energy metabolite pyruvate may clarify the metabolic effects of the intervention. Prospective comparative studies, including analysis of outcome on a larger multicenter basis, are necessary to assess the long term clinical benefits of this procedure.

Keywords: Traumatic brain injury; brain tissue oxygen; energy metabolites; hyperoxygenation.

\section{Introduction}

Evidence that cerebral blood flow (CBF) is decreased but oxygen consumption is increased in the acute phase after severe brain injury $[4,26,27,41]$ suggests that treatment aimed at preventing cerebral ischaemia may improve outcome. Secondary mechanisms, such as neuroexcitotoxicity can worsen brain swelling and intracranial pressure (ICP), further impairing cerebral perfusion pressure (CPP) and brain oxygenation [9, 19, 23, 24, 47]. The challenge, therefore, is two-fold, to maintain sufficient blood supply to the brain and to improve oxygen delivery to brain cells $[38,63,67]$. A consensus has been reached that CPP of around $70 \mathrm{mmHg}$ may provide optimal blood supply to the brain [43]. In contrast, there is no definition of the optimal values for the fraction of inspired oxygen $\left(\mathrm{FIO}_{2}\right)$ or for brain tissue oxygen tensions ( $\mathrm{PtiO} 2)$.

Measurements of PtiO2, using various commercially available sensors, can provide a continuous assessment of brain oxygenation and microdialysis enables monitoring of brain energy metabolites including lactate concentration. The role of intracerebral lactate after head injury has been much debated recently [5]. It has been hypothesized that lactate constitutes the preferred substrate over glucose in neurons, especially in times of increased metabolism [30-32, 55-57]. This is because neurons use lactate by converting it to pyruvate which then enters the mitochondrial Krebs-cycle to produce ATP [5], as long as mitochondria are functioning 
$[14,58]$. Thus, an increased lactate level may have a dual significance: it may be either a sign of anaerobic metabolism, or of hyperglycolysis independent of aerobic conditions.

Although an $\mathrm{FIO}_{2}$ of 0.4 is usually employed in intubated and mechanically ventilated patients to maintain $100 \%$ oxygen blood saturation, higher values have been proposed. A number of groups have analyzed the relation between arterial oxygen tension $(\mathrm{ABGAO} 2)$ and $\mathrm{PtiO} 2$ in patients with severe head injury [3, 37, 52] and Menzel et al. reported that, by increasing $\mathrm{ABGAO} 2$ through ventilatory oxygen enhancement, $\mathrm{PtiO} 2$ was elevated also [35].

WE hypothesized that, by increasing $\mathrm{FIO}_{2}$ from 0.4 to 1.0, PtiO2 would be improved and that this might influence brain metabolism as reflected in measurements of glucose and lactate production. We report studies aimed to test this hypothesis through observation of the effects of increasing $\mathrm{FIO}_{2}$ to 1.0 for 6 hours in a group of severely head injury patients. The studies were made in the first day after injury, as soon as possible after stabilization of the monitoring sensors and we also analyzed the relationship between CPP and PtiO2.

\section{Materials and methods}

A total of 20 patients who had suffered a severe head injury, with a Glasgow coma score $\leq 8$, were included in the study. The study protocol was approved by the local Ethics Committee for Human Research. Informed consent was obtained from the families of the patients. All patients were directly referred to our centre either by helicopter or by ambulance in the first 3 hours after trauma, were intubated, sedated and treated to relax muscles. At the time of admission patients were ventilated with $\mathrm{FIO}_{2}$ 1.0. A cranial CT scan was performed as soon as possible. A patient who was not expected to survive the next 24 hours was excluded from this study, but was treated according to our standard protocol. If an emergency operation was not required, cranial bolts for measurement of PtiO2, ICP and a brain microdialysis catheter were introduced. If a patient required an emergency operation, the sensors were placed in the operating theatre after closure of the skin. A run-intime with the Licox sensor and the microdialysis sensor of between one to two hours after insertion was allowed before collection of data for analysis. For data monitoring, a mobile intensive care $\mathrm{HP}^{\circledR}$ monitor was upgraded with an interface for the multi-modality-monitor MMM (Licox ${ }^{\circledR}$ GMS, Germany). After the study period, the data were downloaded onto a computer. Microsoft ${ }^{\circledR}$ Access and Excel programs were used for data storage and processing. The indices collected were mean arterial blood pressure (MABP), end-tidal $\mathrm{CO}_{2}$ (EtCO2), CPP, ICP, $\mathrm{PtiO}$, core temperature and heart rate.

Oxygen challenge period in the first 24 hours after injury (period A)

The 6 hour "oxygen challenge test" was started as soon as the "runin-time" for the sensors was over. The patient was ventilated with an $\mathrm{FIO}_{2}$ of 1.0; thereafter, $\mathrm{FIO}_{2}$ was gradually reduced to the usual values (0.4) according to standard management.

\section{Period following oxygen challenge (period B)}

For comparison we used the 6 hour period immediately following the oxygen challenge period A and named it period B. Data collection was not different to Period A.

\section{Baseline $\mathrm{FIO}_{2}$}

$\mathrm{FIO}_{2}$ values before to Period A were around 0.6. After the oxygen challenge Period $\mathrm{A}, \mathrm{FIO}_{2}$ was reduced to 0.6 and from there stepwise to baseline values $\left(\mathrm{FIO}_{2} 0.3-0.4\right)$ that depended on the patient's condition.

\section{Bolts and ICP sensor}

A commercially available intraparenchymal ICP transducer (Integra ${ }^{\circledR}$ Neurosciences, Camino, San Diego, California, USA) was used and fixed to the frontal skull.

\section{Licox}

For measurement of the oxygen tension in brain tissue, the Licox oxygen sensor with a $13 \mathrm{~mm}^{2}$ sensitive area (Licox, Integra ${ }^{\circledR}$ Neurosciences) was used in each of the 20 patients. The sensor was introduced, along with a microdialysis catheter, into a separate burr hole. The data were collected online through the Licox Multimodal Monitor MMM. The sensor was placed in the frontal area, in an area of brain judged by the first CT not to be contused.

\section{Microdialysis}

A custom microdialysis probe $\left(\mathrm{CMA}^{\circledR}\right.$, Sweden), with a molecular mass cut-off level of $20 \mathrm{kDa}$, was used along with the Licox probe. The microdialysis probe was perfused using a CMA microdialysis pump with saline at a flow rate of $0.5 \mu \mathrm{l} / \mathrm{min}$. Samples were collected every hour. The samples were then frozen for later analysis for glucose and lactate using an automated enzymatic assay with the YSI 2700 (Yellow Springs ${ }^{\circledR}$, USA). At the end of the study, the microdialysis probes were collected and inspected for leakage and kept for measurement of the in vitro recovery rates for glucose and lactate. A sample volume of $25 \mu \mathrm{l}$ in total was needed for the analysis for glucose and lactate with the YSI 2700.

\section{Data collection and storage}

The data were collected online using a Hewlett Packard ${ }^{\circledR}$ ICU Monitor mounted on a mobile unit and upgraded with an interface to enable connection to the Licox ${ }^{\circledR}$ MMM. The data were downloaded on to an Acer $^{\circledR}$ Notebook at a frequency of 2 per minute. For the 20 patients, 160812 separate data points were collected; these represented a total of 80406 minutes of monitoring. Data were stored in a Microsoft ${ }^{\circledR}$ Access database.

\section{Statistical analysis}

To assess correlations between $\mathrm{FIO}_{2}, \mathrm{ABGAO} 2$ and $\mathrm{CPP}$ versus $\mathrm{PtiO} 2$, we calculated the r-values for each patient the $24 \mathrm{~h}$ observation period. Thereafter, a one sample t-test was run over the r-values to calculate the significance. To analyze the 2 observation periods $\mathrm{A}$ and $\mathrm{B}$ for $\mathrm{FIO}_{2}$ and ABGAO2 versus $\mathrm{PtiO} 2$, the means of the 6 hour oxygen challenge period (A) and of the 6 hours after the oxygen challenge period (B) were calculated for each patient. A paired t-test over the mean values of all patients was run to assess the significances of any differences. For calculation of the peak correlation analysis between CPP and PtiO2 in all patients, Lorentzian peak regression analysis was used [33]. To determine 
the significance of any differences in lactate during the two observations periods (A and B), an ANOVA test was used. For all results the threshold of significance was set at a p-value of 0.05 . The calculations were done using Sigma Plot $2001^{\circledR}$, SPSS $^{\circledR}$ and Statistica ${ }^{\circledR}$.

\section{Results}

A total of 20 patients suffering from severe head injury were studied, 13 males ( $40 \pm 16$ years) and 7 females ( $37 \pm 20$ years). The average initial Glasgow Coma Score was 6 . The demographic data are summarized in Table 1. The intracerebral sensors (Licox and ICP) were placed in 17 cases on the right frontal side and in 3 cases on the left frontal side. Microdialysis was placed in 19 patients; the samples were used for analysis in 15 patients. In 2 cases the dialysate showed a red discoloration indicating the sensor was ruptured, the samples were discarded. Five patients required immediate surgery.

\section{Fraction of inspired oxygen and arterial blood gas oxygen versus PtiO2}

$\mathrm{FIO}_{2}$ and $\mathrm{PtiO} 2$ were significantly positively correlated $(\mathrm{p}<0.0001)$ (t-test over the r-values from the correlation of all patients in the first 24 hours (Fig. 1a). A similar

Table 1. Demographic data. Probe placement refers to the location of the ICP, PtiO2 and microdialysis sensors

\begin{tabular}{|c|c|c|c|c|c|c|}
\hline Patient & Age & Sex & Initial GCS & Probe placement & Injury type & Emergency op. \\
\hline 1 & 25 & male & 4 & right frontal & DIA & 0 \\
\hline 2 & 56 & male & 6 & right frontal & SDH and DIA & 1 \\
\hline 3 & 24 & female & 3 & right frontal & DIA & 0 \\
\hline 4 & 59 & male & 6 & right frontal & DIA & 0 \\
\hline 5 & 21 & female & 9 & right frontal & DIA & 0 \\
\hline 6 & 28 & male & 6 & right frontal & DIA & 0 \\
\hline 7 & 69 & male & 4 & right frontal & DIA bifronto-basal & 0 \\
\hline 8 & 17 & male & 6 & right frontal & DIA & 0 \\
\hline 9 & 53 & male & 9 & right frontal & EDH and DIA & 1 \\
\hline 10 & 22 & female & 9 & right frontal & DIA & 0 \\
\hline 11 & 73 & female & 8 & right frontal & DIA & 0 \\
\hline 12 & 51 & male & 9 & right frontal & SDH and DIA & 2 \\
\hline 13 & 21 & male & 3 & right frontal & DIA & 0 \\
\hline 14 & 48 & female & 10 & left frontal & DIA & 0 \\
\hline 15 & 25 & male & 4 & right frontal & DIA & 0 \\
\hline 16 & 22 & female & 7 & right frontal & DIA & 0 \\
\hline 17 & 41 & male & 6 & left frontal & SDH and DIA & 1 \\
\hline 18 & 54 & female & 3 & right frontal & SDH and DIA & 1 \\
\hline 19 & 28 & male & 3 & left frontal & DIA & 0 \\
\hline 20 & 48 & male & 8 & right frontal & DIA & 0 \\
\hline
\end{tabular}

$D I A$ Diffuse axonal Injury, SDH Subdural hematoma, $E D H$ Epidural hematoma.
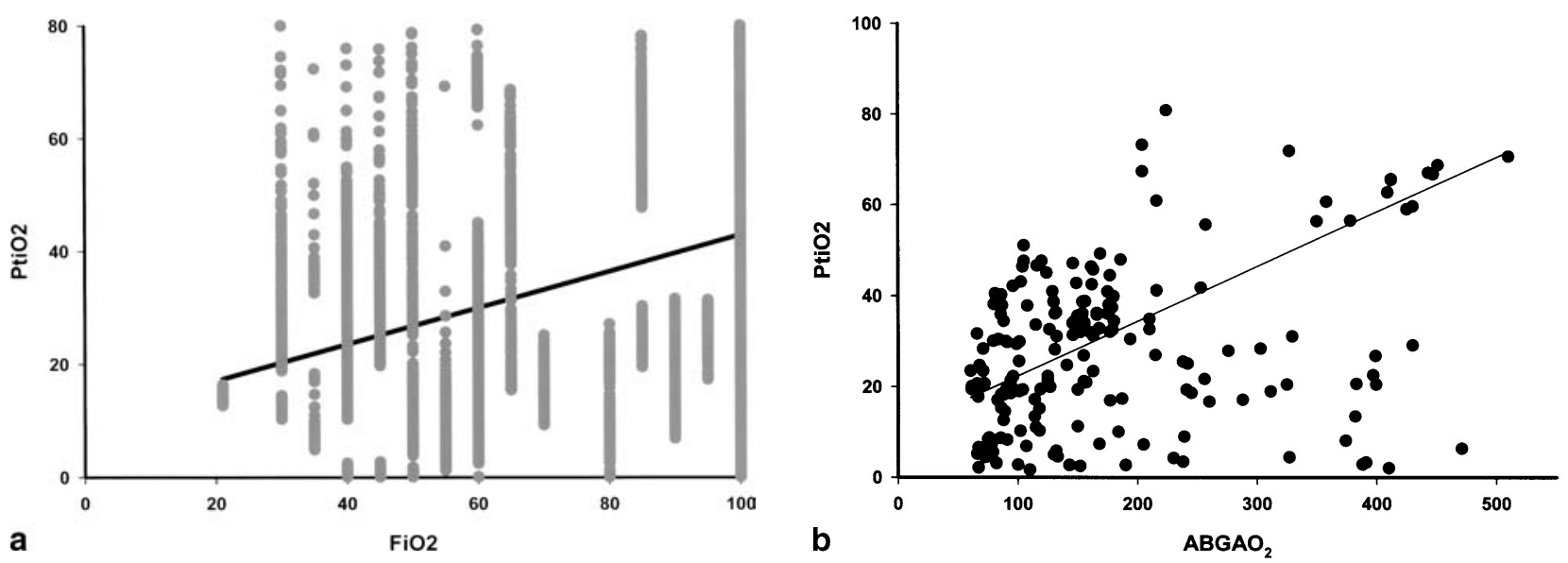

Fig. 1. (a) Combined regression analysis between $\mathrm{FIO}_{2}$ and $\mathrm{PtiO} 2$ of all patients after TBI. Test t-test over the r-values of each patient showed a significance of $\mathrm{p}<0.0001$. (b) Combined regression analysis between $\mathrm{ABGAO} 2$ and PtiO2 of all patients after TBI $(r=0.5)$. The $t-$ test on the $r$-values of each patients showed a significance of $p<0.0001$ 
significant positive correlation between $\mathrm{ABGAO} 2$ and $\mathrm{PtiO} 2$ was observed $(\mathrm{p}<0.0001)$. The $\mathrm{r}$-value of the combined data of all patients in one plot is $r=0.5$, as shown in Fig. 1b.

Of a sub-group of 6 patients with low $\mathrm{PtiO} 2$ $(<10 \mathrm{mmHg})$ and high $\mathrm{ABGAO} 2$ and $\mathrm{FIO}_{2}$ (1.0) during monitoring (Figs. 1a and 1b), 4 died in ICU. The other 2 patients had low $\mathrm{PtiO} 2$ levels from the start and reacted more slowly to an increase in $\mathrm{FIO}_{2}$. The Licox probes were in the vicinity of haemorrhagic contusions in these cases.

The stability of PtiO2 over the Period A is shown as the percentage change over the 6 hours in relation to the values of the first 10 minutes of Period A (Fig. 2).

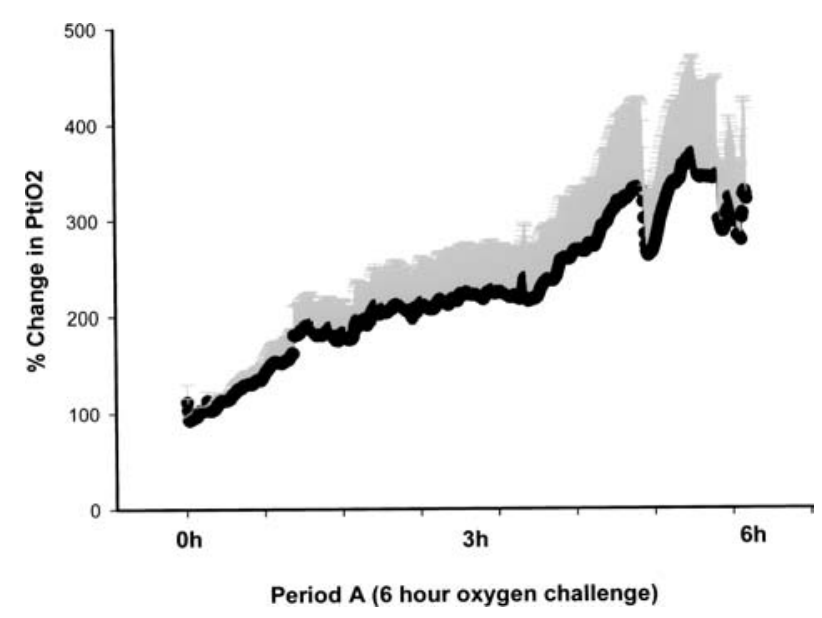

Fig. 2. Mean percentage increase in $\mathrm{PtiO} 2(+\mathrm{SEM})$ during the Period $\mathrm{A}\left(\mathrm{FIO}_{2} 1.0\right)$ of all 20 patients. The reference is the first 10 minutes of Period A
6 hour oxygen challenge and PtiO2-ABGAO2

PtiO2 was significantly higher $(\mathrm{p}<0.001)$ during period A $(52.3 \pm 10.1)$ as compared to period $\mathrm{B}$ $(20.7 \pm 3.9)$. ABGAO2 was similarly higher during period A $(\mathrm{p}<0.0001)$ (Fig. 3).

Analysis of cerebral perfusion

pressure versus $\mathrm{PtiO} 2$

The analysis of cerebral perfusion pressure versus $\mathrm{PtiO} 2$ showed a significant positive correlation $(\mathrm{p}<0.001)$ (t-test of the r-values of all patients). Analyzing all patients together in one plot with a Lorentzian peak correlation analysis, demonstrated a peak of PtiO2 at a CPP of $78 \mathrm{mmHg}$ (Fig. 4).

The 6 hour oxygen challenge brain microdialysate glucose and lactate dynamics

The dialysate lactate values during period A were significantly lower $(\mathrm{p}=0.015)$ than during period $\mathrm{B}$ (ANOVA Test) (Fig. 5). Analysis of dialysate glucose levels did not show significant difference (Fig. 6).

The mean values and standard deviations of the values of MABP, ICP, CPP and EtCO2 during periods A and B are listed in Table 2.

\section{Relationship between EtCO2 and arterial blood gas oxygen values}

The online measured EtCO2 values were $8.1 \mathrm{mmHg}$ lower than the directly measured arterial blood gas oxygen tensions $(n=1365)$, confirming that the patients

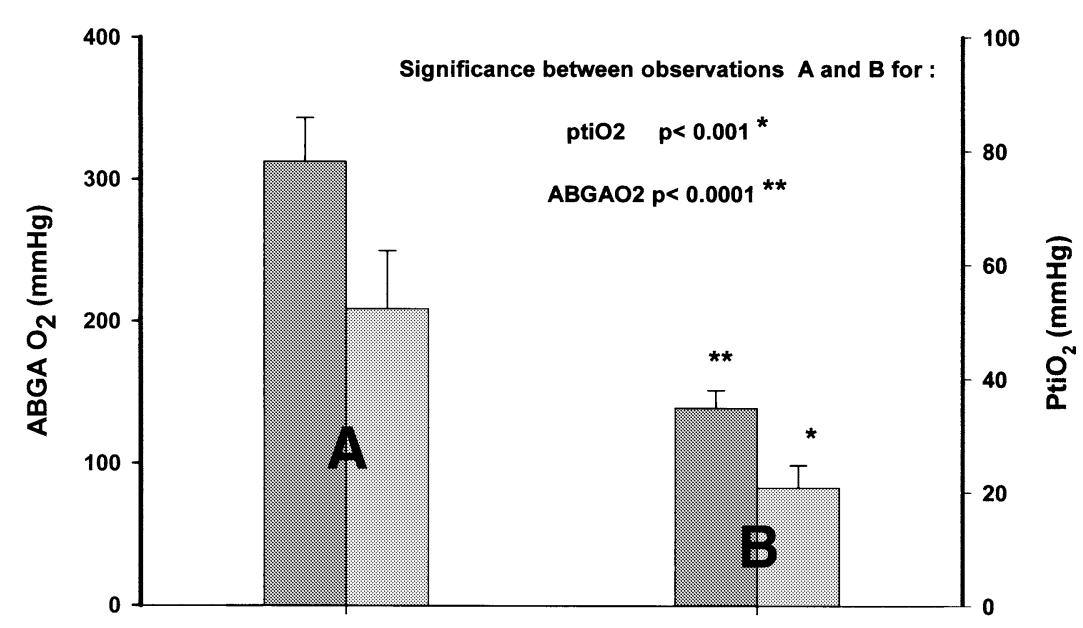

Arterial Blood Gas Oxygen Tension ( $\mathrm{ABGAO}_{2}$ )

Brain Tissue Oxygen (ptiO ${ }_{2}$ )
Fig. 3. Oxygen challenge (period A) and comparison of $\mathrm{ABGAO} 2$ and $\mathrm{PtiO} 2$ in the subsequent period $\mathrm{B}, \mathrm{ABGAO} 2$ and $\mathrm{PtiO} 2$ were significantly higher in $\mathrm{A}$ than in $\mathrm{B}$ 


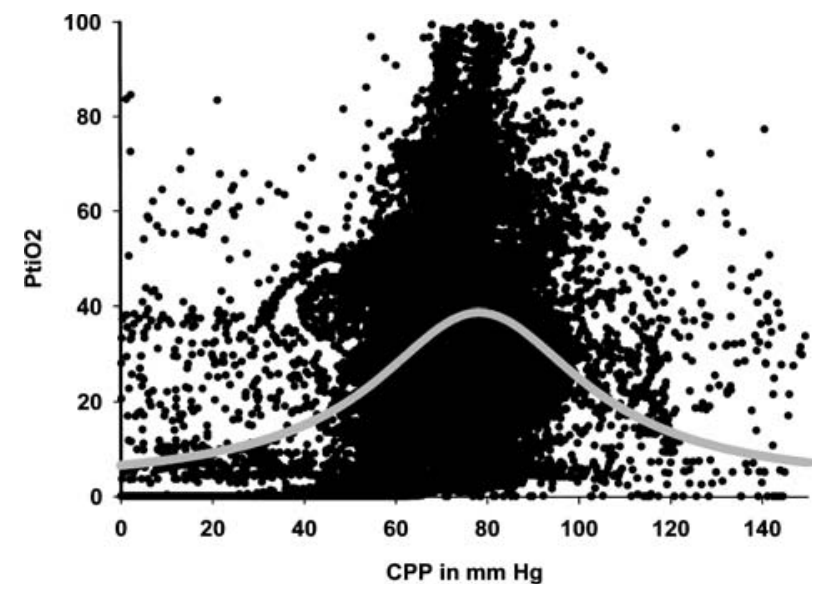

Fig. 4. Lorentzian peak correlation analysis between $\mathrm{CPP}$ and $\mathrm{PtiO} 2$ of all patients in one plot, showing a peak in best $\mathrm{PtiO} 2$ at a CPP value of $78 \mathrm{mmHg}$

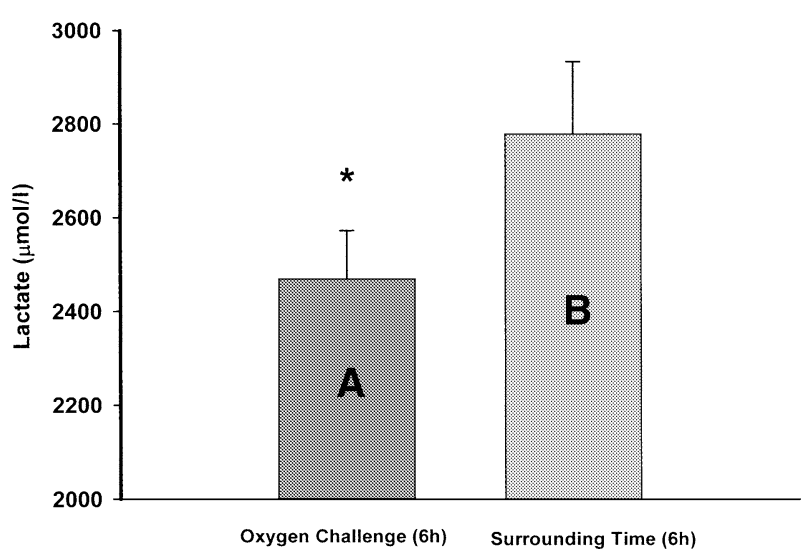

Fig. 5. Bar plot comparing dialysate lactate during the oxygen challenge period and the subsequent time when dialysate lactate was higher $(\mathrm{p}=0.015)$

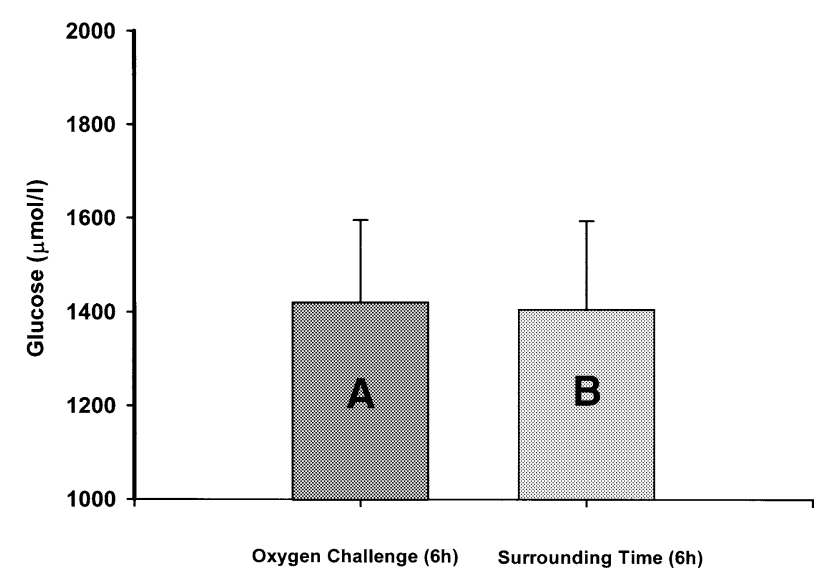

Fig. 6. Bar plot comparing dialysate glucose during the oxygen challenge period and the subsequent time
Table 2. Hemodynamic data (mean values and the standard deviations) during Period $A$ and Period $B$

\begin{tabular}{lllllr}
\hline & \multicolumn{1}{l}{$\mathrm{A}$} & & & \multicolumn{2}{l}{$\mathrm{B}$} \\
\cline { 2 - 3 } \cline { 6 - 6 } & Mean & SD & & Mean & SD \\
\hline MAP & 86.4 & 14.8 & & 81.4 & 14.0 \\
ICP & 17.2 & 15.4 & & 18.3 & 17.5 \\
CPP & 69.3 & 14.9 & & 63.1 & 18.5 \\
PECO2 & 26.9 & 4.1 & & 28.2 & 3.9 \\
\hline
\end{tabular}

$\mathrm{n}=17104$.

$M A B P$ Mean arterial blood pressure; $I C P$ intracranial pressure; $C P P$ cerebral perfusion pressure; $\mathrm{EtCO} 2$ end tidal $\mathrm{CO}_{2}$.

were moderately hyperventilated according to our guidelines (Table 2).

\section{Discussion}

Our study demonstrates that an increase in $\mathrm{FIO}_{2}$ can lead to a significant increase in arterial blood gas oxygen tensions (ABGAO2) and brain tissue oxygen tensions (PtiO2) in recently head injured patients. Furthermore, increasing $\mathrm{FIO}_{2}$, and hence increasing $\mathrm{PtiO} 2$, was associated with a decreased brain microdialysis lactate, without a change in brain microdialysis glucose. CPP was positively correlated with $\mathrm{PtiO} 2$ with a peak at a CPPvalue of $78 \mathrm{mmHg}$.

\section{General considerations}

This study was performed prospectively, excluding patients unlikely to survive the first 24 hours. This is one reason that fewer patients with very low $\mathrm{PtiO} 2$ values were included, as compared to those reported in other studies of similar severely head injured patients $[3,69]$. In our study, each patient was their own control for the microdialysis results. We chose this design of study because baseline values for microdialysis, glucose and lactate differ in different patients with a severe head injury, as a result of different types of injury. To reduce these effects, microdialysis sensors and oxygen sensors were placed in non-contused areas. However, contusions sometimes develop after a delay and the use of multiple probe placement has been proposed to gain a more global view of changes in brain metabolism [25, 60].

The sequence of observations, i.e. Period A to Period $\mathrm{B}$, is likely to have influenced our findings. $\mathrm{FIO}_{2}$ was decreased only after the oxygen challenge so that the difference in brain tissue microdialysis lactate values might have been greater between Period A and Period B. We plan to expand the present protocol and study a 
"real" control group, in which there is no oxygen enhancement.

Two different probes are in clinical use to measure brain tissue oxygen tensions: the Clark type electrode as used in the Licox ${ }^{\circledR}$ and, previously, Paratrend ${ }^{\circledR}$ probes, and an optical system as used in the Neurotrend ${ }^{\mathbb{B}}$. Different dynamics of oxygen measurement and different effects of increasing $\mathrm{FIO}_{2}$ have been described for the two systems, and studies testing the sensors simultaneously are ongoing $[46,22]$.

\section{Fraction of inspired oxygen and brain tissue oxygen}

There are reports of a positive correlation between values of $\mathrm{PtiO} 2$ and of different induced arterial oxygen tensions [29, 37, 66, 70]. Thus, Van Santbrink et al. and Menzel et al. described an increasing brain tissue oxygen in patients with severe head injury in response to increasing arterial oxygen tensions [36, 66]. Differences in baseline values of $\mathrm{PtiO} 2$ and in how these respond to increased arterial oxygen tensions may result from the use of different oxygen sensors placed at different depths and in different areas of the brain. In our study the sensor was placed at the same depth, in relation to the bolt system, in each patient.

Low brain tissue oxygen tensions have been associated with poor outcome (PtiO2 $<20 \mathrm{mmHg}$ ) and fatal outcomes (PtiO2 $<10 \mathrm{mmHg}$ ) [3, 16]. Van den Brink et al. [65] reported low $\mathrm{PtiO} 2$ in $57 \%$ of patients with severe head injury despite full treatment. Our demonstration that, if $\mathrm{PtiO} 2$ values remain low, despite an oxygen challenge $\left(\mathrm{FIO}_{2} 1.0\right)$, most patients died, may help to identify very severe injury. On the other hand, it has also been demonstrated that a marked increase in brain tissue oxygen after inducing $\mathrm{FIO}_{2} 1.0$ can be associated with a poor outcome $[35,66]$. This has been linked to impaired cerebral vasoreactivity. Normally arterial hyperoxia causes vasoconstriction and there is about a $20 \%$ reduction of $\mathrm{CBF}$ when ventilation with $\mathrm{FIO}_{2} 1.0$ is used, as long as vasoreactivity is maintained [48]. This suggests that an oxygen reactivity challenge might help to identify patients who might benefit from early increased oxygen ventilation, but more data are needed.

\section{Microdialysis glucose and lactate}

There is evidence from studies using microdialysis that neuroexcitatory induced hyperglycolysis occurs after experimental head injury [11-13]. Glutamate released by neurons after injury is taken up by astrocytes and Pellerin and Magestretti hypothesized that this drives glycolysis. This may relate to the hyper glycolysis observed with PET in patients suffering severe head injury $[4,45]$ and in accord with findings with microdialysis of increased glutamate and lactate and reduced glucose $[9,18]$. This neuroexcitotoxic response occurs very soon after injury and may be missed in the clinical circumstances. Menzel et al. performed studies in a similar time period after severe head injury but placed less emphasis on an immediate start and included a hyperoxygenation challenge [36]. Lactate levels in the microdialysis fluid were reduced during the oxygen challenge period, and glucose showed a trend to lower values. Overall the values they observed with microdialysis were lower than the values reported in our study. This difference may be caused by the different microdialysis flow rates used, $2.0 \mu \mathrm{l} / \mathrm{min}$ versus $0.5 \mu \mathrm{l} / \mathrm{min}$ in ours. Rossi and Stocchetti previously commented that the reduction in lactate reported by Menzel et al. may be due either to an improvement in aerobic glucose metabolism or simply to a lower oxygen availability as a result of reduction in cerebral blood flow following an increase in arterial blood gas oxygen [50]. However we found no change in glucose levels during the oxygen challenge which suggests an improvement in cerebral glucose utilization. Analysis of pyruvate levels in relation to those of the excitatory transmitter glutamate might elucidate this topic.

\section{Cerebral perfusion pressure and brain} tissue oxygen

As discussed above, the mismatch between cerebral perfusion [7] and metabolic need [4] after TBI can lead to ischaemia, resulting in brain swelling and poor outcome. Prolonged hyperventilation $(\mathrm{PaCO} 2<25 \mathrm{mmHg}$ ) has been shown to be associated with a worse outcome and should be used only with additional monitoring of blood flow or oxygenation [21, 53, 54, 65] for which CPP is the best available method. The EBIC Guidelines propose that CPP is maintained between $60-70 \mathrm{mmHg}$, whereas the ABIC Guidelines support slightly higher values, above $70 \mathrm{mmHg}[28,43]$. As definitive evidence is lacking, firm recommendations cannot be made. In our study, CPP was positively correlated with $\mathrm{PtiO} 2$ and the Lorentzian peak correlation analysis demonstrated a peak of $\mathrm{PtiO} 2$ at a CPP value around $78 \mathrm{mmHg}$. This observation supports the view that CPP 
should be maintained over $70 \mathrm{mmHg}$. However, CPP should not be elevated excessively because the blood brain barrier may be disrupted, which could result in brain edema. Based upon studies of cerebral autoregulation, Czosnyka et al. reported a similar value of optimal CPP of around $80 \mathrm{mmHg}[15,61]$ with higher values possibly disrupting cerebral autoregulation. However interpretation of the results of this Lorentzian peak correlation analysis does not permit conclusions about a definite threshold level for clinical circumstances.

Several studies have analyzed the relation between $\mathrm{CPP}$ and $\mathrm{PtiO} 2$. In an experimental study using a swine model, brain $\mathrm{PtiO} 2$ reflected changes in $\mathrm{CPP}$ or $\mathrm{CBF}$ [49]. In one clinical study of patients with mild to severe head injury, low $\mathrm{PtiO} 2$ could not be predicted on the basis of CPP alone [51], but in another, Bardt et al. reported low $\mathrm{PtiO} 2$ values in relation with low CPP values in patients with severe head injury [3]. Stocchetti et al. and Bruzzone et al. described a relation between CPP and $\mathrm{PtiO} 2$ in areas with disrupted autoregulation in patients with severe head injury and subarachnoid haemorrhage [8, 62]. Taken together, these results suggest that $\mathrm{PtiO} 2$ may be influenced by CPP, independently of tissue demand. This effect may be especially important when autoregulation is disrupted but may have an upper limit after which autoregulation breakthrough may dominate. Measuring the pressure reactivity index online as an index of the state of autoregulation [6], may be helpful in differentiating between patients who can benefit from a more forced CPP therapy, from those for whom therapy aimed at an improvement of blood brain barrier integrity is more appropriate.

\section{Free radicals}

Enhanced free radical production is a major concern of prolonged oxygen therapy and has been demonstrated in ischaemia reperfusion [10, 40, 44] or fluid percussion models [20, 44]. However, the concern is probably not justified, because many studies show no elevation of free radical production following oxygen enhancement $[1,17$, 39, 42, 44]. Clinical trials with free radical scavengers such as PEG-SOD and tirilazad-mesylate have neither proved nor disapproved a role for free radicals in head injury $[34,68]$. Potentially irreversible lung injury has been described by using an $\mathrm{FIO}_{2}$ of 1.024 to 36 hours [2] and these regimens therefore should be avoided $[59,63,64]$.

\section{Conclusion}

Increasing the fraction of inspired oxygen $\left(\mathrm{FIO}_{2}\right)$ is a simple manoeuvre and seems to influence brain metabolism, as shown by the reduction in brain microdialysis lactate. Either alone or in combination with therapies aimed at optimising CPP and/or reestablishment of the blood brain barrier, it may minimize secondary injury following severe head injury. Experimental studies, using standardized trauma models are needed along with multicenter, prospective, randomized, clinical studies with analysis of outcome.

\section{Acknowledgments}

We thank Ann C. Rice, Ph.D., Department of Neurosurgery, Medical College of Virginia, Virginia Commonwealth University, USA and Isabelle Clemetson, M.D., Department of Diagnostic Radiology, University of Bern, Switzerland, for proof reading the manuscript.

\section{Support}

This study was supported by the Novartis Stiftung, Basel, Switzerland, the Extrakredit of the University of Bern, Switzerland, as well as the Josephine Clark Foundation, Bern, Switzerland.

\section{References}

1. Agardh C, Zhang H, Smith ML, Siesjo BK (1991) Free radical production and ischemic brain damage: influence of postischemic oxygen tension. Int J Dev Neurosci 9: 127-138

2. Barber RE, Lee J, Hamilton WK (1970) Oxygen toxicity in man. A prospective study in patients with irreversible brain damage. N Engl J Med 283: 1478-1484

3. Bardt T, Unterberg A, Haertl R, Kiening K, Schneider G, Lanksch W (1998) Monitoring of brain tissue PO2 in traumatic brain injury: effect of cerebral hypoxia on outcome. Acta Neurochir (Wien) [Suppl] 71: 153-156

4. Bergsneider M, Hovda D, Shalmon E, Kelly D, Vespa P, Martin N, Phelps M, McArthur D, Caron M, Kraus J, Becker D (1997) Cerebral hyperglycolysis following severe traumatic brain injury in humans: a positron emission tomography study. J Neurosurg 86 : 241-251

5. Bittar P, Charnay Y, Pellerin L, Bouras C, Magistretti P (1996) Selective distribution of lactate dehydrogenase isoenzymes in neurons and astrocytes of human brain. J Cereb Blood Flow Metab 16: $1079-1089$

6. Bouma GJ, Muizelaar J, Bandoh K (1992) Blood pressure and intracranial pressure-volume dynamics in severe head injury relationship with cerebral blood flow. J Neurosurg 77: 15-19

7. Bouma G, Muizelaar J, Choi S, Newlon P, Young H (1991) Cerebral circulation and metabolism after severe traumatic brain injury: the elusive role of ischemia. J Neurosurg 75: 685-693

8. Bruzzone P, Dionigi R, Bellinzona G, Imberti R, Stocchetti N (1998) Effects of cerebral perfusion pressure on brain tissue PO2 in patients with severe head injury. Acat Neurochir (Wien) [Suppl] 71: $111-113$

9. Bullock R, Zauner A, Woodward J, Myseros J, Choi S, Ward J, Marmarou A, Young H (1998) Factors affecting excitatory amino 
acid release following severe human head injury. J Neurosurg 89: $507-518$

10. Cao W, Carney JM, Duchon A, Floyd RA, Chevion M (2002) Oxygen free radical involvement in ischemia and reperfusion injury to brain. Neurosci Lett 26: 233-238

11. Chen T, Qian YZ, Di X, Zhu JP, Bullock R (2000) Evidence of lactate uptake after rat fluid percussion brain injury. Acta Neurochir (Wien) [Suppl] 76: 359-364

12. Chen T, Qian YZ, Rice A, Zhu JP, Di X, Bullock R (2000) Brain lactate uptake increases at the site of impact after traumatic brain injury. Brain Res 861: 281-287

13. Chen T, Qian Y, Di X, Rice A, Zhu J, Bullock R (1999) Lactate/glucose dynamics after rat fluid percussion brain injury. J Neurotrauma 17: 135-142

14. Clausen T, Zauner A, Levasseur J, Rice AC, Bullock MR (2002) Induced mitochondrial failure in the feline brain: implications for understanding acute post-traumatic metabolic events. Brain Res 908: $35-48$

15. Czosnyka M, Smielewski P, Piechnik S, Steiner LA, Pickard JD (2001) Cerebral autoregulation following head injury. J Neurosurg 95: 756-763

16. Dings J, Jaeger A, Meixensberger J, Roosen K (1998) Brain Tissue pO2 and outcome after severe head injury. Neurol Res 20: S71-S75

17. Doppenberg E, Rice MR, Di X, Young H, Woodward J, Bullock $R$ (1998) Increased free radical production due to subdural hematoma in the rat: effect of increased inspired oxygen fraction. J Neurotrauma 15: 337-347

18. Doppenberg E, Zauner A, Bullock R, Ward J (1998) Correlations between brain tissue oxygen tension, carbon dioxide, $\mathrm{pH}$ and cerebral blood flow - a better way of monitoring the severely injured brain? Surg Neurol 49: 650-654

19. Fiskum G (2000) Mitochondrial participation in ischemic and traumatic neural cell death. J Neurotrauma 17: 843-855

20. Globus MY, Alonso O, Dietrich D, Busto R, Ginsberg MD (1995) Glutamate release and free radical production following brain injury: effects of posttraumatic hypothermia. J Neurochem 65 : 1704-1711

21. Gopinath SP, Valadka A, Uzura M, Robertson C (1999) Comparison of jugular venous oxygen saturation and brain tissue PO2 as monitors of cerebral ischemia after head injury. Crit Care Med 27: $2337-2345$

22. Hoelper B (2002) Unpublished data

23. Katayama Y, Becker D, Tamura T, Hovda D (1990) Massive increases in extracellular potassium and the indiscriminate release of glutamate following concussive brain injury. J Neurosurg 73 : 889-900

24. Katayama Y, Maeda T, Koshinaga M, Kawamata T, Tsubokawa T (1995) Role of excitatory amino acid-mediated ionic fluxes in traumatic brain injury. Brain Pathol 5: 427-435

25. Kiening KL, Schneider GH, Bardt TF, Unterberg AW, Lanksch WR (1998) Bifrontal measurements of brain tissue-PO2 in comatose patients. Acat Neurochir (Wien) [Suppl] 71: 172-173

26. Levasseur J, Alessandri B, Reinert M, Bullock M, Povlishock J, Kontos H (2000) Fluid percussion injury transiently increases then decreases brain oxygen consumption in the rat. J Neurotrauma 17: $101-112$

27. Levasseur J, Qian Y, Alessandri B, Bullock R, Povlishock J, Kontos H (1998) Changes in oxygen utilization after rat fluid percussion injury. J Neurotrauma 15: 879

28. Maas A, Dearden M, Teasdale G, Braakman R, Cohadon F, Iannotti F, Karimi A, Lapierre F, Murray G, Ohman J, Persson L, Servadei F, Stocchetti N, Unterberg A (1997) EBIC-Guidelines for management of severe head injury in adults. Acta Neurochir (Wien) 139: 286-294
29. Maas A, Fleckenstein W, Jong DD (1993) Effect of increased ICP and decreased cerebral perfusion pressure on brain tissue and cerebrospinal fluid oxygen tension. In: Avezaat C, Eijndhoven V, Maas A (eds) Intracranial pressure VIII. Springer Berlin Heidelberg New York Tokyo

30. Magistretti P, Pellerin L (1999) Cellular mechanisms of brain energy metabolism and their relevance to functional brain imaging. Philos Trans R Soc Lond B Biol Sci 354: 1155-1163

31. Magistretti P, Pellerin L, Rothman D, Shulman R (1999) Energy on demand. Science 283: 495-497

32. Magistretti P, Sorg O, Yu N, Martin J, Pellerin L (1993) Neurotransmitters regulate energy metabolism in astrocytes: implications for the metabolic trafficking between neural cells. Dev Neurosci 15: 306-312

33. Marquardt DW (1963) J Soc Ind Appl Math 11: 431-441

34. Marshall LF, Marshall SB (1995) Pitfalls and advances from the international tirizalad trial in moderate and severe head injury. J Neurotrauma 12: 929-932

35. Menzel M, Doppenberg E, Zauner A, Soukup J, Reinert M, Clausen T, Brockenbrough P, Bullock R (1999) Cerebral oxygenation in patients after severe head injury-monitoring and effects of arterial hyperpoxia on cerebral blood flow, metabolism and intracranial pressure. J Neurosurg Anesth 11: 240-251

36. Menzel M, Doppenberg E, Zauner A, Soukup J, Reinert M, Bullock R (1999) Increased inspired oxygen concentration imporves brain tissue oxygenation and tissue lactate after severe human head injury. J Neurosurg 91: 1-10

37. Menzel M, Rieger A, Roth S, Soukup J, Peuse C, Hennig C, Molnar P, Furka I, Radke J (1998) Simultaneous continuous measurement of $\mathrm{pO} 2, \mathrm{pCO} 2, \mathrm{pH}$ and temperature in brain tissue and sagittal sinus in a porcine model. Acta Neurochir (Wien) [Suppl] 71: 183-185

38. Miller JD (1985) Head injury and brain ischaemia - Implications for therapy. Br J Anaesth 57: 120-130

39. Mink R, Dutka AJ (1995) Hyperbaric oxygen after global cerebral ischemia in rabbits does not promote brain lipid peroxidation. Crit Care Med 23: 1398-1404

40. Morimoto T, Globus MY, Busto R, Martinez E, Ginsberg MD (1996) Simultaneous measurement of salicylate hydroxylation and glutamate release in the penumbral cortex following transient middle cerebral artery occlusion in rats. J Cereb Blood Flow 16: 92-99

41. Muizelaar JP (1996) CBF and management of the head-injured patient. In: Narayan R, Wilberger J, Povlishock JT (eds) Neurotrauma. McGraw-Hill, New York St. Louis, San Francisco pp 553-561

42. Murakami N, Horinouchi T, Sakurai M, Ejima Y, Matsukawa S, Kato M, Tabayashi K (2001) Hyperbaric oxygen therapy given 30 minutes after spinal cord ischemia attenuates selective motor neuron death in rabbits. Crit Care Med 29: 814-818

43. The Brain Trauma Foundation (2000) The American Association of Neurological Surgeons. The joint section of neurotrauma and critical care. J Neurotrauma 17: 449-627

44. The Brain Trauma Foundation (2000) The American Association of Neurological Surgeons. The joint section of neurotrauma and critical care. Guidelines for cerebral perfusion pressure. J Neurotrauma 17: 507-511

45. Pellerin L, Magistretti P (1994) Glutamate uptake into astrocytes stimulates aerobic glycolisis: a mechanism coupling neuronal activity to glucose utilization. Neurobiology 91: 10625-10629

46. Quinones-Hinojosa A, Morabito D, Rollins M, Holland M, Manley GT (2001) In vitro comparison of two different brain tissue oxygen monitors. J Neurotrauma 18: 1137

47. Reinert M, Khaldi A, Doppenberg E, Zauner A, Bullock R (2000) High extracellular potassium and its correlates after severe head 
injury: relationship to high intracranial pressure. J Neurosurgery 93: $800-807$

48. Rockswold G (1996) Hyperbaric oxygen therapy in head injury. In: Narayan R, Wilberger JR, Povlishock JT (eds) Neurotrauma. McGraw-Hill, New York, pp 393-399

49. Rossi S, Balestreri M, Spagnoli D, Bellinzona G, Valeriani V, Bruzzone P, Maestri M, Stocchetti N (2000) Oxygen delivery and oxygen tension in cerebral tissue during global cerebral ischemia: a swine model. Acta Neurochir (Wien) [Suppl] 76: 199-202

50. Rossi S, Stocchetti N (1999) Comment: brain tissue oxygenation. J Neurosurg 91: 1065-1067

51. Sahuquillo J, Amoros S, Santos A, Poca MA, Panzardo H, Dpminque L, Pedraza S (2000) Does an increase in cerebral perfusion pressure always mean better oxygenated brain? A study in head-injured patients. Acta Neurochir (Wien) [Suppl] 76: $457-462$

52. Sarrafzadeh A, Kiening K, Bardt T, Schneider G, Unterberg A, Lanksch W (1998) Cerebral oxygenation in contusioned vs nonlesioned brain tissue: monitoring of $\mathrm{PtiO} 2$ with Licox and Paratrend. Acta Neurochir (Wien) [Suppl] 71: 186-189

53. Sarrafzadeh A, Sakowitz OW, Callsen TA, Lanksch WR, Unterberg AW (2002) Detection of secondary insults by brain tissue pO2 and bedside microdialysis in severe head injury. Acta Neurochir (Wien) [Suppl] 81: 319-321

54. Schneider GH, Sarrafzadeh A, Kiening KL, Bardt TF, Unterberg AW, Lanksch WR (1998) Influence of hyperventilationon brain tissue- $\mathrm{PO} 2, \mathrm{PCO} 2$ and $\mathrm{pH}$ in patients with intracranial hypertension. Acta Neurochir (Wien) [Suppl] 71: $62-65$

55. Schousboe A, Westergaard N, Waagepetersen H, Larsson O, Bakken I, Sonnewald U (1997) Trafficking between glia and neurons of TCA cycle intermediates and related metabolites. Glia 21: $99-105$

56. Schurr A, Miller J, Payne R, Rigor B (1999) An increase in lactate output by brain tissue serves to meet the energy needs of glutamateactivated neurons. J Neurosci 19: 34-39

57. Schurr A, West C, Rigor B (1988) Lactate supported synaptic function in the rat hippocampal slice preparation. Science 240: $1326-1328$

58. Siesjo B (1978) Brain energy metabolism. Wiley, Chichester New York Brisbane Toronto

59. Singer MM, Wright F, Stanley LK, Roe BB, Hamilton WK (2002) Oxygen toxicity in man: a prospective study in patients after openheart surgery. N Engl J Med 283: 1473-1478

60. Stahl N, Ungerstedt U, Nordstrom C (2001) Brain energy metabolism during controlled reduction of cerebral perfusion pressure in severe head injuries. Intensive Care Med 27: $1215-1223$

61. Steiner LA, Czosnyka M, Piechnik S, Smielewski P, Chatfield D, Menon DK, Pickard JD (2002) Continuous monitoring of cerebrovascular pressure reactivity allows determination of optimal cerebral perfusion pressure in patients with traumatic brain injury. Crit Care Med 30: 733-738

62. Stocchetti N, Chieregato A, De Marchi M, Croce M, Benti R, Grimoldi N (1998) High cerebral perfusion pressure improves low values of local brain tissue $\mathrm{O} 2$ tension (PtiO2) in focal lesions. Acta Neurochir (Wien) [Suppl] 71: 162-165

63. Thomas S, Prins M, Samii M, Hovda D (2000) Cerebral metabolic response to traumatic brain injury sustained early in development: a 2-deoxy-D-glucose autoradiographic study. J Neurotrauma 17: 649-665

64. Van de Water JM, Kagey KS, Miller IT (2002) Response of the lung to six to 12 hours of $100 \%$ oxygen inhalation in normal man. N Engl J Med 283: 621-626
65. van den Brink W, van Santbrink H, Steyerberg E, Avezaat CJ, Suazo JA, Hogesteeger C, Jansen WJ, Kloos LM, Vermeulen J, Maas A (2000) Brain oxygen tension in severe head injury. Neurosurgery 46: $868-876$

66. VanSantbrink H, Maas A, Avezaat C (1996) Continuous monitoring of partial pressure of brain tissue oxygen in patients with severe head injury. Neurosurgery 38: 21-31

67. Yoshino A, Hovda D, Kawamata T (1991) Dynamic changes in local cerebral glucose utilization following cerebral concussion in rats: evidence of a hyper and a subsequent hypometabolic state. Brain Res 561: 106-119

68. Young B, Runge JW, Waxman KS (1996) Effects of pegorgotein on neurologic outcome of patients with severe head injury. JAMA 276: 538-543

69. Zauner A, Bullock R, Young HF (1995) Continuous monitoring of brain oxygen, $\mathrm{CO} 2, \mathrm{pH}$ and temperature in brain tissue using a single sensor. J Neurotrauma 12: 468

70. Zauner A, Clausen T, Alves OL, Rice A, Levasseur J, Young HF, Bullock R (2002) Cerebral metabolism after fluidpercussion injury and hypoxia in a feline model. $\mathrm{J}$ Neurosurg 97: 643-649

\section{Comment}

This prospective observation cohort study, conducted on 20 patients with severe head injury describes the effects of increasing FiO2 on brain tissue PtiO2, lactate and glucose concentrations in microdialysate of the brain and further describes the relation between CPP and brain tissue $\mathrm{PtiO} 2$. Monitoring of brain tissue oxygen tension and microdialysis were introduced into clinical practice approximately 10 years ago. Microdialysis has remained mainly confined to research settings, but the technique of brain tissue oxygen monitoring has, partly because of its simplicity, gained wide acceptance in neuro intensive care and is now routinely employed in many centers. Studies in TBI have shown a frequent occurrence of low values of $\mathrm{PtiO} 2$ in the initial 12 to 24 hours and the occurrence of such values is related to poorer outcome. We are now at the turning point where results of this currently accepted monitoring technique can be translated into improved therapeutic strategies, aiming at increasing the chances for better outcome in individual patients. This manuscript represents a significant step forward in this direction. The authors convincingly demonstrate that increasing $\mathrm{FiO} 2$ improves brain tissue oxygen tension. They further show that during the oxygen challenge period of 6 hours lactate levels are lower in microdialysate of the brain than in the following period. These observations would support the concept for improving cerebral oxygenation following severe head injury by simply increasing FiO2. There remain however many clinical and also basic questions which need to be answered before this approach should be routinely adopted in neuro-intensive care. Somewhat unfortunately this manuscript focuses on means and averages in the population described. This approach for goes opportunities for- individualized targeted management based on multimodality monitoring. It may well be that for instance the slope of diffusion of oxygen between the arterial circulation and the brain tissue may be relevant. The authors for instance described that in patients in whom low $\mathrm{PtiO} 2$ was not increased on elevating $\mathrm{FiO} 2$ fatal outcome occurred in 4 out of 6 cases; presumably in the other 2 cases in which this phenomenon was observed, the local values were influenced by the presence of hemorrhage contusions. This observation highlights the limitations and potential pitfalls of a regional technique. It should further be recognized that measured values of $\mathrm{PtiO} 2$ with the technique employed represent average values from the recruitment area surrounding the probe. This recruitment area is determined by the number, spatial distribution and diameter of local vessels contributing to tissue perfusion. In this regard equal 
attention should be paid to improving local microcirculation as well as it to improving FiO2. The observation from the Lorentzian analysis showing a peak of PtiO2 at a CPP of $78 \mathrm{mmHg}$ is of interest and would support the concept of maintaining CPP between 70 and $80 \mathrm{mmHg}$. However here again the limitations of analysis of averages is pertinent and hopefully in the future more targeted values in individual patients can be determined by results of multimodality monitoring.

Although the authors correctly state that prospective randomised clinical studies will be required to demonstrate clinical efficacy of oxygen targeted management in head injury I doubt whether such will be achievable and is in fact even necessary. Personally I would be quite happy if functional studies such as fMRI or PET studies would show positive effects of oxygen targeted management on cerebral function.

A. Maas

Rotterdam

Correspondence: Michael Reinert M.D., Department of Neurosurgery, Inselspital Bern, University of Bern Switzerland, 3010 Bern, Switzerland. e-mail: michael.reinert@neurochirurgie-bern.ch 